\title{
EPRU
}

Economic Policy Research Unit

Institute of Economics

University of Copenhagen

Studiestræde 6

DK-1455 Copenhagen $\mathrm{K}$

DENMARK

Tel: (+45) 35324411

Fax: (+45) 35324444

Web: http//:www.econ.ku.dk/epru/

\section{Strategic Campaigns and \\ Redistributive Politics}

\author{
Christian Schultz
}

2003-03

ISSN 0908-7745

The activities of EPRU are financed by a grant from The National Research Foundation 


\title{
Strategic Campaigns and Redistributive Politics
}

\author{
Christian Schultz ${ }^{* \dagger}$
}

March 2003

\begin{abstract}
The paper investigates strategic campaigning in a model of redistributive politics in a society with many groups and two parties. Campaigns are informative, and parties can target campaigns to different groups. Voters are uncertain about whether parties favor special groups. The parties will seek to target campaigns at groups where most votes are gained by informing about policies. In equilibrium campaigning will be most intensive in groups where the uncertainty is largest and where voters are most mobile. These groups will therefore be very well informed about policy and will accordingly be favored by the parties' policies.
\end{abstract}

JEL: D72, D82, H40

Keywords: Political Economy, Redistribution, Information

\footnotetext{
*Institute of Economics, University of Copenhagen, Studiestraede 6, DK 1455 Copenhagen K, Denmark, CIE, EPRU and CES-ifo. E-mail: Christian.Schultz@econ.ku.dk, web: www.econ.ku.dk/CSchultz

†I benefitted from discussions with Guiseppe Bertola, Douglas Hibbs, Niels Henrik Mörch von der Fehr and Jean Tirole as well as the comments of seminar audiences in CORE, Goteborg, Florence, Oslo and Paris and EEA in Venice, while working on this paper.
} 


\section{Introduction}

Political campaigns are an important part of electoral democracies. Candidates spend endless days on the campaign trail and parties spend huge amounts of campaign money. Clearly, the campaigns have a purpose: influence the preferences of voters, so they are induced to vote for the campaigning party. It seems well documented that they actually work, see e.g. Green and Krasno (1988) or Gerber (1998). How campaigns exactly achieve this effect can vary. Some voters may be attracted just by the fact that a party campaigns intensely and perhaps with nice campaigns. In the literature such campaigns are usually called persuasive, cf. Baron (1984). On the other hand, parties also spend considerable resources on informative campaigns, informing about a their policies or perhaps about other parties' policies. ${ }^{1}$. Such campaigns would seem beneficial from a social perspective as they allow voters to make more informed choices. On the other hand, they also have implications for the parties' strategic struggle, and the policies, which are adopted in the end. In this paper we will consider the effects of strategic, informative campaigning on redistributive politics in a society where redistribution is among different groups and where parties can target their campaigns to the various groups. The main questions we are interested in are how the parties will spend their limited campaign resources, and which effects this will have on policies?. Which groups will benefit? Are such campaigns to be considered good or bad?.

A party's vote share in a group increases when the group's voters learn that the party offers the group better policies than the other party. The share increases more, the more swing voters the group contains - the more mobile the voters of the group are. Therefore, groups where the a priori uncertainty

\footnotetext{
${ }^{1}$ Holbrook (1996), Alvarez (1998) and Just et (1990) provides evidence on the information generated in electoral campaigns and that television advertising increases the information held by voters.
} 
about the parties' policies is large and voters are mobile will be targeted by campaigns and these groups will end up being very well informed. The high information level in these groups makes parties offer these groups beneficial policies. In the end these groups will benefit from the strategic campaigning, redistributive policies will favor them.

The basic model of the paper is the model of redistributive politics originally introduced by Lindbeck and Weibull (1987) and extended by Dixit and Londregan (1996). These papers show that parties will favor groups, where voters are mobile. Our results can be seen as reinforcing this: these groups will be targeted by parties' campaigns. They will therefore be well informed and this in turn makes them even more attractive from the point of view of the parties. In equilibrium these groups will gain even more. In this sense, there is a campaign-multiplier, campaigns reinforce the effects of voter mobility. Dahlberg and Jonasson (2002) find strong support for the Lindbeck-Weibull model in data from a Swedish temporary grant program.

An important and much discussed issue is whether campaigns are good or bad from the point of view of society. The adverse effects of lobbying is by now well described and understood, see e.g. the book by Helpman and Grossman (2001). The lobbying literature usually assumes that campaigning is persuasive, so money directly buys votes. I show that campaigning funds are also valuable for parties if campaigning is informative, and hence the incentive to induce lobby group payments remains. Although lobbies will not be considered in this paper, the model could serve as a building block in a model of lobbying.

Informative campaigns are often considered good since they allow voters to make informed choices. However, the results of this paper points to another effect. Informative campaigning creates a particular distribution of information in the electorate, which in turn affects real policies. A group's information level is determined by the parties' strategic incentives to gain 
most votes from the limited campaign money rather than considerations of fairness. This favors groups, who already gain from the strategic struggle among the parties, the mobile groups. So, informative campaigning make the distribution of policies over groups more unequal than if all groups had the same level of information. In this sense a limit on campaign spending (or finances) would make for a more equal distribution in society. ${ }^{2}$

A party will campaign in groups where it has good news to reveal, either that its policy is better or that the other party's policy is worse than expected. So, parties will never campaign in the same groups. This may seem counterfactual, but is true since we limit attention to informative campaigning. In the real world both persuasive and informative campaigns are present. As is well known from for instance Baron (1984) parties will have incentives to direct persuasive campaigns to the same groups of voters.

We assume that the parties commit to their policy proposals before the election and that they inform truthfully about these. Clearly, this is a benchmark case. In the real world politicians may lack a commitment device, however, reputational forces will punish politicians who grossly disregard preelectoral promises. Most of the world remembers Bush's (in)famous "Read my lips" statement. Furthermore, we also want to investigate the effects of informative campaigning under the positive presumption, that they really are informative. Clearly, if they are cheap talk, not much is gained by such campaigns, they are either akin to persuasive campaigns or just a waste of money.

Voters are assumed to be rational Bayesians: if uninformed a voter will seek to derive whatever information is contained in the fact that neither of the parties informed her. She will update her prior belief that a party is of a special type using Bayes' rule and the equilibrium strategies of the parties.

The organization of the paper is as follows: Section 2 shortly discusses

\footnotetext{
${ }^{2}$ Since the model is one of pure redistribution, all allocations are Pareto efficient.
} 
some related literature. Section 3 introduces the model. Equilibrium is defined in section 4 . Section 5 derives equilibrium policies and campaign choices, and finally some concluding remarks are offered in section 6 .

\section{Some related literature}

The effects of information on redistributive policies are considered in Strömberg (1999). In Strömberg's model information is provided by mass media rather than by parties. Voters are uncertain about the parties' policies, since they are unsure about the size of the different groups. Mass media then have a role informing voters about the policies of the parties. As in the present paper parties will target informed groups. Strömberg also shows that there will be a bias in the policy, since the mass media will have an own interest in informing particular groups which are attractive to advertisers. In Strömberg (2000) he considers the impact of the spreading of radio for the allocation of funds under New Deal in the thirties in the US. There is a clear pattern that more informed groups - groups with a high share of households owning a radio - receive larger funds as predicted by the theory. Although in a different context, Besley and Burgess (2000) report the same kind of result for India. Indian states with larger newspaper circulation tend to receive more public food distribution and calamity relief expenditure. Compared with the papers of Strömberg and Besley and Burgess, the important new element in the present paper is that the parties choose the distribution of information strategically as a part of the electoral struggle.

Informative campaigning is also considered by Austen-Smith (1987) in a model with a uni-dimensional policy space. He considers a model where there is uncertainty about parties' policies. Risk adverse voters are therefore reluctant to vote for parties whose policies they only have stochastic information about. Informing the voters reduces the risk. Austen-Smith shows that in 
equilibrium informative campaigning makes ideological parties choose policies closer to the median voter's preferred policy. While highly innovative, a problem with the analysis is that the source of the uncertainty is unexplained (in equilibrium, the positions of the parties are actually certain) and it is unexplained how campaigning contributes to reducing the uncertainty.

Prat (1999) is interested in whether a ban should be put on lobbies contributions to parties. He considers informative campaigning in a model where two office-seeking candidates may have different competencies. An interest group receives non-verifiable information about the competency about the candidates. The interest group offers money to the parties in return for a favorable policy position. The money is used on non-informative campaigning, but a separating equilibrium exists in which voters infer the candidates' competency from the amount of campaign spending. Campaigns are thus both good and bad for voters, good since they provide information about the candidates' competency, and bad since the parties distort policy in order to obtain money from the interest group. Whether a ban on campaigns will benefit voters is therefore not clear. Potters, Sloof and Van Winden (1997) also discuss signalling through campaigning.

Coate (2001) offers an interesting analysis of informative campaigns in a model of a uni-dimensional policy space. Two parties are policy-motivated, they each propose a candidate, which may be moderate or extreme (partisan). Party members prefer a partisan candidate, while moderate voters prefer a moderate candidate. Voters do not know the type of candidate only his party affiliation. Informative campaigning can inform about the characteristic of a candidate. Such campaigning benefits moderate candidates as it is possible to attract moderate voters from the other party. Parties receive contributions from partisan interest groups. Coate shows that a limit on contributions reduces expected campaign spending but it also decrease the likelihood that parties will select moderate candidates. In Coate (2002) he 
considers informative campaigning regarding candidates' qualities or competencies. Politics is uni-dimensional and extreme lobby groups are informed about the qualities of candidates. A trade off arises, since qualified candidates will be able to raise money from lobby groups and can inform the electorate about their superior quality. This is good. However, the candidates modify their policy in a more extreme direction in order to cater to the extreme lobby groups, which is bad. Coate show that under some conditions a limit on campaign contributions may then be Pareto improving. While the negative effects of informative campaigning in Coate's papers derives from the power of extreme lobby groups our argument is different. There are no lobby groups in the present model, the unequal distribution resulting from informative campaigning in this paper derives from the unequal distribution of information induced by the campaigning.

Finally, Ortuno-Ortin and Schultz (2000) considers informative campaigning in a model of a uni-dimensional policy space where policy motivated parties receive funding for campaigning from the state. They show that informative campaigns contribute to make the parties' policies converge.

All of the above-mentioned papers with informative campaigning consider uni-dimensional policy spaces. Their aim is to consider different legislative regimes regarding campaign finance, with an aim at discussing the socially best. The present paper, on the other hand, focuses on the distributional aspects of the effects of strategic informative campaigning. It shows that there are distributional consequences of informative campaigning.

\section{Basics}

We consider a society with two parties $A$ and $B$. There are $n$ groups $i=$ $1, \ldots, n$. Each group contains a continuum of citizens of size 1. Each party proposes a distribution of per capita consumption before an election, $c_{A}$ 
$=\left(c_{A 1}, \ldots, c_{A n}\right)$, and $c_{B}=\left(c_{B 1}, \ldots, c_{B n}\right)$, respectively. The proposals have to fulfil the budget constraint

$$
\sum_{i} c_{A i}=\Omega
$$

The parties are committed to these proposals, the winner of the election implements its proposal.

Voters become informed about policies in a variety of ways: through media, conversation, attending meetings, etc., and through parties' campaigns. For the model, the important feature is that the parties can affect the share of informed voters by campaigning. Each party has an amount, $M$, of campaign money, which can be used informing the different groups of voters about the policies. We will assume that information is hard, a party cannot lie about policies. Evidently, this is a benchmark case. But as touched upon in the introduction, it is a benchmark case of interest. Political life has its reputations, a politician caught lying will be front page news, journalists and independent experts enjoy such prey $^{3}$. Furthermore, as also argued in the introduction, we are interested in evaluating informative campaigns on the presumption that they actually are informative. Voters, who remain uninformed about the policies, rely on their expectations. They are uncertain about the exact policies chosen by the parties but derive whatever inferences can be drawn from the fact that they remain uninformed.

We model the uncertainty as originating from an uncertainty about the parties' preferences. The voters may be unsure about which fraction of the

\footnotetext{
${ }^{3}$ A recent Danish experience is the March 1998 general election. Polls showed a very close race between the ruling Socialdemocrats and the right wing opposition. Prime Minister Poul Nyrup Rasmussen made a very popular pledge not to change an early retirement scheme, which most economists found very unwise. The Sociademocrats won the election and Prime Minister Nyrup reneged on his promise half a year later, changing the early retirement scheme. He immediately made front page news as a liar, the Socialdemocrats plummeted in the polls and never regained the lost. They lost the next election in 2001.
} 
party is the most influential, how the different fractions strike deals within the party and they may also be unsure about leading politicians' preferences. As an example, consider the newly elected Margaret Thatcher in UK. Everybody knew that she was a right winger, but how stern and how tough she would be for instance in relation to trade unions was uncertain. Likewise, the newly elected Tony Blair for sure had changed some priorities in Labour but how much?

For simplicity, we assume that the voters are only uncertain about one of the parties' preferences, but this not crucial for the results. The important feature is that there is some uncertainty about the relative difference between the parties' policies, which is (also) the case in the formulation chosen here. One could think of the party, whose preferences voters are unsure about, as the party which has been in opposition for some time. Contrary to the incumbent, the voters have not had an opportunity to see which policy the challenging party chose in the recent past. Just as was the case with Thatcher and Blair.

While voters are uncertain about one of the parties' preferences, both parties know each other's preferences. The motivation for this assumption is that parties are lead by professional politicians who spend time and effort to understand their competitors, they are assisted by full time employees, whose job it is exactly to gather such information and make the relevant assessments, and they are often in daily contact with leading politicians from other parties. For the leaders of the parties it is an important part of the strategic struggle to know the opponent. The incentive for a voter is much smaller (actually zero in our model, where there is a continuum of citizens in each group). In short, there is asymmetric information among voters and parties.

In principle, a party can choose to inform about its own policy only, about the other party's policy only, or about both parties policies. However, 
rational voters who observe a campaign message from a party, should ask themselves why the party withholds some information if it indeed does. We will assume that the cost of reaching a voter is the same regardless of whether the information is about one of both of the parties' policies. The idea is that the (significant part of the) cost of campaigning is associated with reaching the voters. A voter, who is informed by a party will then know that the party costlessly could provide more information, if the party "hides" information. Voters will then rationally unravel whatever information a party seeks to hide. Assume for instance, that party $A$ informs about its own policy only. A voter, who is informed by $A$, will then infer that $A$ is not interested in informing about party $B^{\prime} s$ policy, since this policy actually is good for the voter. Had the policy been bad, party $A$ would be more than happy to inform about it. Rational voters will therefore be able to infer party $B^{\prime} s$ policy. As there are only two types of party $B$, there are only two possible equilibrium policies of party $B$ and voters are completely informed. A similar argument excludes that it is possible to inform about the other party's policy only. This imply that it is not an option for a party to inform about only one party's' policy. When a party decides to campaign in a group, it reveals information about both parties' policies. Notice that the same unraveling argument applies even if there are more types of parties. A party would always want to reveal the most positive information, if it does not voters will exclude this case etc.

In the end a party therefore only has two options: inform about both parties' policies or not inform at all.

Following the literature on informative advertising (see Butters (1977) and Grossman-Shapiro (1984)) it is assumed that the fraction of informed voters are increasing in the amount of campaigning. If party $A$ spends $m_{A i}$ on informing voters in group $i$ about policies in group $i$, then the fraction $\psi\left(m_{A i}\right)$ of the voters in group $i$ will learn see A's campaign, $\psi$ is increasing 
and strictly concave, $\psi \prime>0$ and $\psi \prime \prime<0$. The first few dollars spent on campaigning are very effective, $\psi \prime(0)=\infty$. Furthermore, we assume that even though a party spends the whole campaign budget in a district, there will be some uninformed voters left, $\psi(M)<1$. The $\psi$ function may in principle depend on the group, some groups may be easier to inform than others. It may also depend on the party; it may be that a party is better to inform a particular group than the other party. We will however disregard such complications. We assume that the probability that an individual voter becomes informed by party $A^{\prime} s$ campaign is the same for all voters in group $i$ and therefore equal to $\psi\left(m_{A i}\right)$. Similarly, a voter becomes informed by party $B^{\prime} s$ campaign with probability $\psi\left(m_{B_{i}}\right)$. For simplicity, we assume that the events that a voter becomes informed from $A$ or become informed from $B$ are independent. The fraction of informed voters in group $i$ is

$$
\Psi_{i}=\psi\left(m_{A i}\right)+\left(1-\psi\left(m_{A i}\right)\right) \psi\left(m_{B i}\right) .
$$

We let $m_{A}=\left(m_{A i}\right)_{i=1}^{n}$ be the distribution of campaign expenditures of party $A$. As can be seen voters can only become informed through the parties' campaigns. At the cost of adding some notation, this could easily be changed, so that the total fraction of informed voters consisted of those informed by the parties and those informed through other channels. In order to keep the exposition simple, we disregard this, this does not affect our qualitative results.

If consumption in group $i$ is $c_{i}$, a voter in the group gets utility

$$
u\left(c_{i}\right)=\ln c_{i} .
$$

Voters may be biased for one of the parties. The bias consists of an individual component as well as a component common for all voters. Voter $v$ in district $i$ has a ideological bias in favor of party $B$, equal to $x_{i v}+y, x_{i v}$ is a personal bias, $y$ a general bias shared by all voters. It represents a common 
shock to preferences in the electorate occurring just before the election, which may be positive or negative ${ }^{4}$. When voter $v$ is informed about the parties' policies, she prefers party $A$ if

$$
x_{i v}+y \leq u\left(c_{A i}\right)-u\left(c_{B i}\right) .
$$

There is a distribution of bias in each district. In district $i$, the bias is given by the distribution function $\Phi_{i}$. To keep the analysis simple, we follow Persson and Tabellini (2000) and assume that $\Phi_{i}$ is the uniform distribution, with support $\left[-\frac{1}{2 \delta_{i}}, \frac{1}{2 \delta_{i}}\right]$ and density $\delta_{i}$. This restriction is inessential, as the results by Lindbeck and Weibull (1987) show. It will save us some concavity assumptions later. The fact that there is a zero mean is also inessential as long as the support is sufficiently large so that $u\left(c_{A i}\right)-u\left(c_{B i}\right)$ (or the expected counterpart considered below) is contained in the support of $\Phi_{i}$. As we show below, it is only the density which matters. The general bias is also uniformly distributed, with mean 0 and density $\theta$. The parties and the voters are informed about the distribution of the biases, but the parties do not know the realization of the general bias $y$ before choosing policies and campaign expenditures.

A voter who is not informed about the parties' policies will form expectations. Her expected utility from consumption if party $A$ wins the election is denoted $E_{A} u_{i}$. When voter $v$ is uninformed, she will prefer party $A$ if

$$
x_{i v}+y \leq E_{A} u_{i}-E_{B} u_{i} .
$$

We can now derive the fraction of votes for party $A$ in district $i$

$$
V_{i}=\Psi_{i} \Phi_{i}\left(u_{i}\left(c_{A i}\right)-u\left(c_{B i}\right)-y\right)+\left(1-\Psi_{i}\right) \Phi_{i}\left(E_{A} u_{i}-E_{B} u_{i}-y\right) .
$$

\footnotetext{
${ }^{4}$ In the recent (2002) German election, the Socialdemocratic Kansler, Schröder, gained support in polls just before the election following severe floodings in southern Germany. Allegedly, Schröder showed leadership. In the model this would be good realization of $y$ for the Socialdemocrats.
} 
Since the individual bias is uniformly distributed with density $\delta_{i}$ and mean 0 , we have

$$
V_{i}=\frac{1}{2}+\delta_{i}\left[\Psi_{i}\left(u_{i}\left(c_{A i}\right)-u\left(c_{B i}\right)\right)+\left(1-\Psi_{i}\right)\left(E_{A} u_{i}-E_{B} u_{i}\right)-y\right]
$$

The total number of votes cast for party $A$ is therefore

$$
V_{A}=\sum_{i=1}^{n} V_{i}
$$

The probability party $A$ wins the election, $p_{A}$, equals the probability that $V_{A} \geq \frac{n}{2}$. This depends on the realization of the general shock to preferences, $y$. Since $y$ is uniformly distributed with mean zero and density $\theta$, we have after a few manipulations

$$
p_{A}=\frac{1}{2}+\frac{\theta}{\delta} \sum_{i=1}^{n} \delta_{i}\left[\Psi_{i}\left(u_{i}\left(c_{A i}\right)-u\left(c_{B i}\right)\right)+\left(1-\Psi_{i}\right)\left(E_{A} u_{i}-E_{B} u_{i}\right)\right]
$$

where $\delta \equiv \sum_{i=1}^{n} \delta_{i}$

There is no generally agreed upon objective for parties. Different strands of literature have made different assumptions. The formulation chosen here is most closely related Wittman (1983), Calvert (1985), Roemer (1997) and Dixit and Londregan (1998). Both parties are partly motivated by power, partly by ideology. If the party wins the election it receives rents $R$. Furthermore, the party cares about a weighted average of voters' utilities in the different groups. Party $A$ 's objective is to maximize

$$
U_{A}=p_{A} R+\sum_{i=1}^{n} u\left(c_{A i}\right)
$$

Notice that the party's proposed policy, $c_{A i}$ - and not the realized consumption in district $i$ - enters in the last part of the utility functions. This follows the formulation in Roemer (1997). This makes for simplicity in our setting, and the exact formulation is inessential; the important feature is that a party is interested both in winning the election and the utility consequences of its policy. This is captured in our formulation. 
While voters know party $A^{\prime} s$ utility function, and therefore know that party $A$ favors no particular group - all groups enter symmetrically in party $A^{\prime} s$ utility function - they are uncertain about how much party $B$ favors different groups. One could imagine that party $B$ has a constituency and there is uncertainty about how attached party $B$ is to the constituency. For simplicity, we restrict the possible types of party $B$ to two. One type favors its constituency, we will call this the attached type, the other is neutral, just as party $A$. Of course, it would be more realistic to assume that there was infinitely many types of party $B$ corresponding to varying degrees of attachment. However, this would also complicate the analysis to follow, we follow the lead of a large literature and restrict attention to the two-type case. The type who favors the constituency has the following utility function

$$
U_{B}^{\beta}=\left(1-p_{A}\right) R+\sum_{i=1}^{n} \beta_{i} u\left(c_{B i}\right) .
$$

The parameters $\beta_{i} \geq 0$ reflect how strongly the attached party $B$ favors different groups, we normalize such that "average favor" is $\sum_{i} \beta_{i} / n=1$. The attached $B$ strictly favors at least one district $i$, so $\beta_{i}>1$, for some $i$. The attached type is denoted type $\beta$. The neutral type of party $B$, type 1 , has the same utility function except the $\beta_{i}^{\prime} s$ all equal one.

The probability that party $B$ is of type $\beta$ is $\pi$, where $0<\pi<1$. This is known by voters, but they do not know the type of party $B$.

If party $A$ 's type was also uncertain, the analysis would be more cumbersome, as there would be four possible configurations of types. However, this would not add qualitatively to the paper. The important issue is that voters in the different groups are unsure about which party proposes the best policy for them. This feature is secured in our formulation. Our formulation seems realistic for the case where party $A$ is the incumbent and voters have experienced the policies chosen by party $A$ in the past and party $B$ is the challenger without a track record of policies. 
The timeline is as follows. First party $B^{\prime} s$ type is realized, this is observed by both parties. Parties then decide on policies and the distribution of campaign expenditures simultaneously. Some voters receive information about the policies and some do not. The uninformed voters form expectations about the policies and voters vote. Finally, the winning party implements policy the it proposed.

\section{Equilibrium}

We solve the model for a Perfect Bayesian Equilibrium. In this equilibrium each party (for $B$ : of both types) seeks to maximize its objective. A voter takes as given the equilibrium strategies of the parties and vote for party $A$ if she is informed and (4) is fulfilled or she is uninformed and (5) is fulfilled, otherwise she votes for $B$. Let e.g. $m_{A i}^{t}$ be the amount of campaign money party $A$ spends informing voters in group $i$, when party $B$ is of type $t \in\{1, \beta\}$. A uninformed voter in group $i$, rationally derives whatever information is contained in the fact that she is uninformed. For instance, if the attached type of party $B$ is known to favor her group, she may think that the fact that she was not informed by party $B$, indicates that party $B$ is not favoring her group after all and that party $B$ is of the neutral type. Formally, she takes the campaign strategies as given and use them to update her prior belief using Bayes' rule. Her posterior belief that party $B$ is of type $t=\beta$ is therefore

$$
\bar{\pi}_{i}=\frac{\left(1-\psi\left(m_{A i}^{\beta}\right)\right)\left(1-\psi\left(m_{B i}^{\beta}\right)\right) \pi}{\left(1-\psi\left(m_{A i}^{1}\right)\right)\left(1-\psi\left(m_{B i}^{1}\right)\right)(1-\pi)+\left(1-\psi\left(m_{A i}^{\beta}\right)\right)\left(1-\psi\left(m_{B i}^{\beta}\right)\right) \pi} .
$$

This is the probability of being uninformed if $B$ is of the attached type and the parties choose campaigns given $B$ is attached, divided with the total probability of being uninformed. As $\psi(M)<1$, we always have that 
$0<\bar{\pi}_{i}<1$. Let the policy of party $B$ of type $t$ be denoted $c_{B}^{t}$. With posterior belief $\bar{\pi}_{i}$, the expected utility to a voter in group $i$ if party $B$ wins the election is

$$
E_{B} u_{i}=\left(1-\bar{\pi}_{i}\right) u\left(c_{B i}^{1}\right)+\bar{\pi}_{i} u\left(c_{B i}^{\beta}\right) .
$$

Although all voters know that party $A$ is neutral, an uninformed voter is uncertain about $A^{\prime} s$ policy since it depends on $B^{\prime} s$ type. For such a voter in group $i$, the expected utility if party $A$ wins the election is

$$
E_{A} u_{i}=\left(1-\bar{\pi}_{i}\right) u\left(c_{A i}^{1}\right)+\bar{\pi}_{i} u\left(c_{A i}^{\beta}\right),
$$

where $c_{A i}^{t}$ is the policy of party $A$ if party $B$ is of type $t$.

Since voters do not observe the distributions of the parties' campaign expenditures, the parties cannot influence the beliefs of voters who remain uninformed. As a consequence, parties also take the expected utilities in (13) and (14) as given. ${ }^{5}$

In equilibrium parties also take each others' strategies as given. Party $A^{\prime} s$ problem is therefore:

$$
\begin{aligned}
& \text { Given } t, \text { and }\left(\bar{\pi}_{i}, c_{B i}^{t}, m_{B i}^{t}\right)_{i=1}^{n} \\
& \max _{c_{A}, m_{A}} p_{A} R+\sum_{i} u\left(c_{A i}\right) \\
& \operatorname{sub} \sum_{i} c_{A i}=\Omega ; \sum_{i} m_{A i}=M ; c_{A i}, m_{A i} \geq 0
\end{aligned}
$$

The attached type of party $B$ has the following problem

$$
\begin{aligned}
& \text { Given } t=\beta, \text { and }\left(\bar{\pi}_{i}, c_{A i}^{\beta}, m_{A i}^{\beta}\right)_{i=1}^{n} \\
& \max _{c_{B}, m_{B}}\left(1-p_{A}\right) R+\sum_{i} \beta_{i} u\left(c_{B i}\right) \\
& \operatorname{sub} \sum_{i} c_{B i}=\Omega ; \sum_{i} m_{B i}=M ; c_{B i}, m_{B i} \geq 0
\end{aligned}
$$

The neutral type's problem is the same, except $\beta_{i}=1$ for all $i$. We can now state

\footnotetext{
${ }^{5}$ If voters were able to observe the campaign expenditures, a party would take into account that beliefs depend on the distribution of expenditures.
} 
Definition. An electoral equilibrium with strategic campaigns consists of policies and campaign expenditures in all groups for both parties $\left(c_{A}^{t}, m_{A}^{t}\right),\left(c_{B}^{t}, m_{B}^{t}\right), t \in\{1, \beta\}$ and expectations for the voters of all groups $\left(E_{A} u_{i}, E_{B} u_{i}\right)_{i=1}^{n}$ such that

1. Each party (and for B: of each type) chooses policies and campaign expenditures to maximize utility as in (15) and (16).

2. Each uninformed voter forms beliefs using the parties' strategies and Bayes' rule and evaluates expected utilities using these beliefs. For instance $E_{A} u_{i}$ is given by (14), where the beliefs are given by (12). The number of votes cast for party $A$ is then given by (6).

Applying a standard fixed point argument, we have the following:

Lemma 1 An equilibrium exists.

Proof. See the Appendix

\section{Campaigns and Policies}

We now consider equilibrium choices of campaigns and policies. For the attached type of party $B$, the first order conditions for an interior maximum are

$$
\begin{aligned}
-\frac{\partial p_{A}}{\partial c_{B i}} R+\beta_{i} u^{\prime}\left(c_{B i}^{\beta}\right) & =\lambda, \\
-\frac{\partial p_{A}}{\partial m_{B i}} R & =\mu .
\end{aligned}
$$

where $\lambda$ is the Lagrange multiplier associated with the budget restriction (1) and $\mu$ is the multiplier associated with the budget restriction for campaigning. The amount of campaign spending is non-negative. If the non-negativity constraint binds in a group $i$, then corresponding derivative, $\frac{\partial p_{A}}{\partial m_{B i}}$, is negative and the optimal choice is $m_{i}=0$. 
Using (9), the first order condition for an interior choice of $c_{B i}^{\beta}$ yields

$$
c_{B i}^{\beta}=\frac{\Psi_{i} \frac{\delta_{i}}{\delta} \theta R+\beta_{i}}{\lambda}
$$

Using the budget constraint to substitute away $\lambda$ we get

$$
c_{B_{i}}^{\beta}=\frac{\Psi_{i} \frac{\delta_{i}}{\delta} \theta R+\beta_{i}}{\sum_{j}\left(\Psi_{j} \frac{\delta_{j}}{\delta} \theta R+\beta_{j}\right)} \Omega .
$$

Although we have not solved for an equilibrium yet, (19) conveys a nice insight. As in the models of Lindbeck and Weibull (1987) and Dixit and Londregan (1996), the party favors a district, where the density of voters at the cutpoint, $\delta_{i}$, is high. Shifting resources to such a district will gain many votes. However, for this effect to work, voters have to be informed about the parties' policies, $\Psi_{i}$ has to be high. The term $\Psi_{i} \frac{\delta_{i}}{\delta} \theta$ equals the expected increase in votes from offering the group a policy which is one util better, so $\Psi_{i} \frac{\delta_{i}}{\delta} \theta R$ is the increase in expected rents to the party from offering such a better policy. Groups with many informed voters will gain, this is just as in Strömberg (2000).

As expected we also see that districts, the attached party $B$ favors, will receive more resources. The first order conditions for the neutral party $B$ are as above with $\beta_{i}=1$, which are also the first order conditions for party $A$. Accordingly,

$$
c_{A_{i}}=c_{B_{i}}^{1}=\frac{\Psi_{i} \frac{\delta_{i}}{\delta} \theta R+\beta_{i}}{\sum_{j}\left(\Psi_{j} \frac{\delta_{j}}{\delta} \theta R+1\right)} \Omega,
$$

Hence, we directly get that the two parties choose the same policies for all districts when party $B$ is neutral. Had party $A$ also been attached to a constituency, so that the utilities of the different groups were given weights $\alpha_{i}$, the only difference would be that the expression for $c_{A i}$ in (20) would have $\alpha_{i}^{\prime} s$ where 1 's occur. 
If $t=\beta$, we can write the surprise - i.e. difference between the actual and the expected utility difference - as

$$
\left(u\left(c_{B i}^{\beta}\right)-u\left(c_{A i}^{\beta}\right)\right)-\left(E_{B} u_{i}-E_{A} u_{i}\right)=\left(1-\bar{\pi}_{i}\right)\left(u_{i}\left(c_{B i}^{\beta}\right)-u\left(c_{A i}^{\beta}\right)\right),
$$

and if $t=1$ as

$$
\left(u_{i}\left(c_{B i}^{1}\right)-u\left(c_{A i}^{1}\right)\right)-\left(E_{B} u_{i}-E_{A} u_{i}\right)=-\bar{\pi}_{i}\left(u_{i}\left(c_{B i}^{\beta}\right)-u\left(c_{A i}^{\beta}\right)\right) .
$$

Using (9) and (17), the first order condition for an interior choice of campaign expenditures, $m_{B i}^{\beta}$, can be written

$$
\frac{\partial \Psi_{i}}{\partial m_{B i}} \frac{\theta \delta_{i}}{\delta}\left(\left(u\left(c_{B i}^{\beta}\right)-u\left(c_{A i}^{\beta}\right)\right)-\left(E_{B} u_{i}-E_{A} u_{i}\right)\right)=\mu
$$

If the left hand side is negative, the non-negativity constraint binds and $m_{B i}^{\beta}$ equals zero.

Suppose party $B$ is attached, $t=\beta$, using (19) and (21) we can rewrite (23)

$\frac{\partial \Psi_{i}}{\partial m_{B i}} \frac{\theta \delta_{i}}{\delta}\left(1-\bar{\pi}_{i}\right)\left(\ln \left(\frac{\Psi_{i} \frac{\delta_{i}}{\delta} \theta R+\beta_{i}}{\sum_{j}\left(\Psi_{j} \frac{\delta_{j}}{\delta} \theta R+\beta_{j}\right)} \Omega\right)-\ln \left(\frac{\theta R \Psi_{i} \frac{\delta_{i}}{\delta}+1}{\sum_{j}\left(\theta R \Psi_{j} \frac{\delta_{j}}{\delta}+1\right)} \Omega\right)\right)=\mu$

since $\sum_{j} \beta_{j}=n$, this reduces to

$$
\frac{\partial \Psi_{i}}{\partial m_{B i}} \frac{\theta \delta_{i}\left(1-\bar{\pi}_{i}\right)}{\delta} \ln \left(\frac{\theta R \Psi_{i} \frac{\delta_{i}}{\delta}+\beta_{i}}{\theta R \Psi_{i} \frac{\delta_{i}}{\delta}+1}\right)=\mu
$$

Hence, an attached party $B, t=\beta$, only campaigns in groups where $\beta_{i}>1$. Recall that $\frac{\partial \Psi_{i}}{\partial m_{B i}}=\left(1-\psi\left(m_{A i}\right)\right) \frac{\partial \psi}{\partial m_{B i}}$, and $\left(1-\psi\left(m_{A i}\right)\right)>0$. Furthermore, $\psi^{\prime}(0)=\infty$, so party $B$ campaigns in all groups where $\beta_{i}>1$. In these groups the policy is surprisingly good and campaigning gives a gain of votes, since $(21)$ is positive. 
When party $B$ is neutral, $t=1$, the first order condition in groups where $B$ campaigns is

$$
-\frac{\partial \Psi_{i}}{\partial m_{B i}} \frac{\theta \delta_{i} \bar{\pi}_{i}}{\delta} \ln \left(\frac{\Psi_{i} \frac{\delta_{i}}{\delta} \theta R+\beta_{i}}{\Psi_{i} \frac{\delta_{i}}{\delta} \theta R+1}\right)=\mu
$$

The left hand side is positive in groups where $\beta_{i}<1$. Party $B$ of type 1 campaigns where its policy is surprisingly good, just as type $\beta$ does.

Reiterating the above steps for party $A$, we find that party $A$ campaigns in groups where party $B$ does not campaign and vice versa. When party $B$ is attached to its constituency, $t=\beta$, party $A$ campaigns in groups where $\beta_{i}<1$ and the first order conditions for choice of campaign expenditures in these groups are

$$
-\frac{\partial \Psi_{i}}{\partial m_{A i}} \frac{\theta \delta_{i}\left(1-\bar{\pi}_{i}\right)}{\delta} \ln \left(\frac{\Psi_{i} \frac{\delta_{i}}{\delta} \theta R+\beta_{i}}{\Psi_{i} \frac{\delta_{i}}{\delta} \theta R+1}\right)=\mu
$$

When $B$ is neutral, $t=1$, then party $A$ campaigns in groups where $\beta_{i}>1$, and the first order conditions for choice of campaign expenditures in these groups are

$$
\frac{\partial \Psi_{i}}{\partial m_{A i}} \frac{\theta \delta_{i} \bar{\pi}_{i}}{\delta} \ln \left(\frac{\Psi_{i} \frac{\delta_{i}}{\delta} \theta R+\beta_{i}}{\Psi_{i} \frac{\delta_{i}}{\delta} \theta R+1}\right)=\mu
$$

Summarizing the above we have

Lemma 2 At most one party campaigns in a group. This is the party whose policy is relatively better than expected for the group's voters. If party $B$ is attached to its constituency (of type $\beta$ ), then party $B$ campaigns in groups $i$ where $\beta_{i}>1$ and party $A$ campaigns in groups where $\beta_{i}<1$. If party $B$ is neutral (of type 1 ) then $B$ campaigns in groups where $\beta_{i}<1$ and $A$ in groups where $\beta_{i}>1$.

There will be campaigning in all districts where $\beta_{i} \neq 1$ and no campaigning in a district where $\beta_{i}=1$. In the latter case there is no uncertainty about 
the policies affecting the district, and neither party has an incentive to spend campaign money in the district.

Now consider a group $i$ where $\beta_{i}>1$. This is a group where party $B$ campaigns if $t=\beta$ and party $A$ campaigns if $t=1$, (12) gives that the posterior belief in such a group is

$$
\bar{\pi}_{i}=\frac{\left(1-\psi\left(m_{B i}^{\beta}\right)\right) \pi}{\left(1-\psi\left(m_{A i}^{1}\right)\right)(1-\pi)+\left(1-\psi\left(m_{B i}^{\beta}\right)\right) \pi}
$$

In a group where $\beta_{i}<1$, party $A$ campaigns if $t=\beta$ and $B$ campaigns if $t=1$, the posterior belief in such a group is therefore

$$
\bar{\pi}_{i}=\frac{\left(1-\psi\left(m_{B i}^{1}\right)\right) \pi}{\left(1-\psi\left(m_{A i}^{\beta}\right)\right)(1-\pi)+\left(1-\psi\left(m_{B i}^{1}\right)\right) \pi}
$$

We now show that there is an equilibrium, where the amount of campaigning, and therefore the information level of a group is independent of the type of party $B$. In this equilibrium, the posterior belief in all groups therefore equals the prior.

Lemma 3 There exists an equilibrium, where the posterior belief in all groups equals the prior. In this equilibrium, the party who campaigns in a group depends on the type of party $B$, but the amount of campaigning in a group is the same independent of the type of party $B$.

Proof. See the Appendix.

The key to the Lemma is that the parties are in a symmetric situation. If party $B$ is of the attached type and $\beta_{i}>1$, then party $B$ has the incentive to campaign in group $i$. The incentive depends on the size of the surprise. If on the other hand party $B$ is unattached, party $A$ campaigns in the group. $A^{\prime} s$ incentive is also governed by the size of the surprise - and the this size is exactly the same as in the case where $B$ campaigns in the group. The 
only difference is the sign. Therefore the two parties have equally strong incentives to campaign in the group, and the amount of campaign spending is independent of the type of party $B$, but who campaigns is not. Since the amount of campaign spending is independent of the type of party $B$, there is actually no new information in being uninformed. Hence, an uninformed voter does not revise her prior, so the posterior belief equals the prior.

In the sequel we will focus on the equilibrium of Lemma 3, where the posterior equals the prior.

Let $m_{i}$ denote the total level of campaigning in group $i$. In the appendix we use the first order conditions (24)-(26) to prove the following Lemma.

Lemma 4 The level of campaigning and information is larger in groups which are mobile and where the uncertainty is large. More formally,.

$$
\left.\begin{array}{c}
\beta_{i}=\beta_{j} \text { and } \delta_{i}>\delta_{j} \\
\delta_{i}=\delta_{j} \text { and }\left(\beta_{i}>\beta_{j}>1 \text { or } \beta_{i}<\beta_{j}<1\right)
\end{array}\right\} \Rightarrow m_{i}>m_{j} \text { and } \Psi_{i}>\Psi_{j}
$$

The parties campaign, where they gain many votes from campaigning, these are groups where the uncertainty is large, and where voters are mobile.

As point of reference consider the case with no campaigns, under the assumptions made, then all groups are equally informed, i.e. in that case $\Psi_{i}=\tilde{\Psi}$ for all groups $i$. Let e.g. $\tilde{c}_{A i}^{t}$ denote the policy of party $A$ offers group $i$ if all groups are equally informed and party $B$ is of type $t, \tilde{c}_{A i}^{t}$ is found by inserting $\tilde{\Psi}$ into equation $(20)^{6}$.

From equations (19), and (20), we know that the consumption level offered to a group is increasing in its information level. Combining this with Lemma 4 directly gives

\footnotetext{
${ }^{6}$ Actually $\tilde{c}_{A i}^{\beta}=\tilde{c}_{A i}^{1}$. This is due to the fact that we only consider uniform distributions of bias in the different groups. If one considers other distributions then the density at the cut-point $\delta_{i}$ depends on both parties policies, and therefore $\tilde{c}_{A i}^{t}$, would depend on $B^{\prime} s$ type.
} 
Theorem 1. Groups which are mobile or where the uncertainty is large gain from strategic campaigning. More formally,

$$
\left.\begin{array}{c}
\beta_{i}=\beta_{j} \text { and } \delta_{i}>\delta_{j} \\
\delta_{i}=\delta_{j} \text { and }\left(\beta_{i}>\beta_{j}>1 \text { or } \beta_{i}<\beta_{j}<1\right)
\end{array}\right\} \Rightarrow c_{A i}^{t}>\tilde{c}_{A i}^{t} \text { and } c_{B i}^{t}>
$$
$\tilde{c}_{B i}^{t}$

Mobile groups and groups where uncertainty is large gain from strategic campaigning. These are groups where campaigns can attract many voters, so they will be targeted by the parties and this makes the groups well-informed, which in turn makes the parties offer the group good policies.

Comparing with the results of Lindbeck and Weibull (1987), we see that there is a campaign-multiplier. Lindbeck and Weibull showed that mobile groups would gain, since they offered a solid vote response to better policies. As is clear from Theorem 1, this effect is reinforced by informative campaigning. The groups are attractive, being mobile, and this also makes them targets for campaigning. This raises the information level making the groups even more attractive for the parties to cater to.

Theorem 1 also point to an unfortunate effect of informative campaigning, at least from an egalitarian point of view - in this model of pure redistribution all allocations are Pareto optimal.. The strategic distortion identified by Lindbeck and Weibull is aggravated by informative campaigning. From this perspective, informative campaigning is not good and a reduction in campaign funds would improve on the situation, since it would lead to a more egalitarian distribution in equilibrium.

Informative campaigns are often considered good since they allow voters to make more informed choices. One may value this feature per se, and one may also conceive of kinds of imperfect information, where more informed choices certainly are preferable. This would for instance be the case if voters were unsure about the state of the economy and the revelation of information made all voters change their preferred policies in the same direction. For a 
discussion of these issues, see Schultz (2002). The present model points to that the question is more complicated. In our model, informative campaigning is not good.

\section{Concluding remarks}

Strategic informative campaigning benefits groups which are very mobile and where the uncertainty about the parties' policies is particularly large. Furthermore the parties will never direct informative campaigns at the same groups. Parties want to reveal positive surprises, and in the nature of things only one party has something positive to reveal.

Groups who are the subject of intensive campaigning ends up being very well informed. Such groups are attractive from the point of view of the parties, many votes can be gained by catering to them. In equilibrium, such groups therefore gain from the strategic campaigning.

In the particular setting of our model, where the uncertainty was about how much the parties (or rather one of the parties) favored different groups, this effect amplified the effect of the preferences for particular groups. However, the uncertainty may concern other issues such as the size of the group or the distribution of bias in the group. In this case it will still be true that groups for which the uncertainty is particularly large will benefit from strategic campaigning. These are the three testable predictions of the model: informative campaigns are intense in groups where there is large uncertainty about policies, in groups which contain many mobile voters, and parties will never use informative campaigns in the same groups. Furthermore, groups which are subject of intense campaigning are groups which gain in the distributional conflict. 


\section{Appendix}

\section{Proof of Lemma 1}

Proof. Since $u$ is strictly concave and $\Phi_{i}$ is the uniform distribution, it follows from (6), (14), (13), (11) and (10) that the objective functions of the parties are strictly concave and continuous in the parties choice variables and continuous in the vector of beliefs $\bar{\pi} \equiv\left(\bar{\pi}_{i}\right)_{i=1}^{n}$. Furthermore, the choice sets of the parties are strictly convex and compact. Hence the vector of optimal choices of the parties given by (15) and (16),

$\sigma \equiv\left(\left(c_{A}^{1}, m_{A}^{1}\right),\left(c_{B}^{1}, m_{B}^{1}\right),\left(c_{A}^{\beta}, m_{A}^{\beta}\right),\left(c_{B}^{\beta}, m_{B}^{\beta}\right)\right)$,is a continuous function of $(\bar{\pi}, \sigma)$. Call this function $s(\cdot)$. We also have that the vector $\bar{\pi}$ is a continuous function of $\sigma$, which takes values in a convex compact set, call this function $p(\bullet)$.

Now consider the compound mapping $\sigma \rightarrow \sigma^{\prime}$ defined by

$$
\sigma^{\prime}=s(p(\sigma), \sigma)
$$

This is a continuous function mapping a compact, convex set into itself, hence it has a fixed point. This fixed point is an equilibrium.

\section{Proof of Lemma 3}

Proof. Suppose that $\bar{\pi}_{i}=\pi$ for all $i$. Consider a group $i$ where $\beta_{i}>1$. If party $B$ is of type $\beta$, party $B$ campaigns in this group and the campaign expenditure is determined by the (set of) first order conditions (24). If on the other hand $t=1$, then party $A$ campaigns in the group, and the campaign expenditure is determined by the set of first order conditions (27). When $\bar{\pi}_{i}=\pi$ for all $i$, then these two set of equations are equivalent and the solutions $\left(m_{B i}^{\beta}\right)_{i \mid \beta_{i}>1}$ and $\left(m_{A i}^{1}\right)_{i \mid \beta_{i}>1}$ are the same. Hence, $m_{B i}^{\beta}=m_{A i}^{1}$. Using (28) we see that in this case it is indeed true that $\bar{\pi}_{i}=\pi$ is a solution to the Bayesian updating of the voters. Clearly the same argument can be applied to groups where $\beta_{i}<1$. In groups where $\beta_{i}=1$, there is no campaigning so trivially, $\bar{\pi}_{i}=\pi$. 


\section{Proof of Lemma 4}

Proof. Lemma 3 implies that we can write the first order condition (24) of party $B$ of type $\beta$ in a group where $\beta_{i}>1$

$$
\frac{\partial \psi}{\partial m_{B i}} \frac{\theta \delta_{i}(1-\pi)}{\delta} \ln \left(\frac{\Psi_{i} \frac{\delta_{i}}{\delta} \theta R+\beta_{i}}{\Psi_{i} \frac{\delta_{i}}{\delta} \theta R+1}\right)=\mu
$$

and there are similar expressions for the other first order conditions. Notice that $\pi$ is a constant, independent of the other variables. Let

$$
\begin{aligned}
X_{B i} \equiv & \frac{\partial^{2} \psi}{\partial\left(m_{B i}\right)^{2}} \ln \left(\frac{\Psi_{i} \frac{\delta_{i}}{\delta} \theta R+\beta_{i}}{\Psi_{i} \frac{\delta_{i}}{\delta} \theta R+1}\right) \\
& +\left(\frac{\partial \psi}{\partial m_{B i}}\right)^{2}\left(\frac{\frac{\delta_{i}}{\delta} \theta R}{\Psi_{i} \frac{\delta_{i}}{\delta} \theta R+\beta_{i}}-\frac{\frac{\delta_{i}}{\delta} \theta R}{\Psi_{i} \frac{\delta_{i}}{\delta} \theta R+1}\right),
\end{aligned}
$$

then $X_{B i}<0$ for $\beta_{i}>1$. By the implicit function theorem, we then get that for $\beta_{i}>1$,

$$
\frac{d m_{B i}^{\beta}}{d \beta_{i}}=-\frac{\frac{1}{\Psi_{i} \frac{\delta_{i}}{\delta} \theta R+\beta_{i}}}{X_{B i}}>0
$$

Hence, the attached type of $B$, campaigns more in group $i$ than group $j$ if $\beta_{i}>\beta_{j}>1$. It campaigns most intensely in groups, which it favors the most. These groups therefore become well informed about policies. These groups also be come well informed if party $B$ is neutral and of type 1 . In this case party $A$ campaigns intensely here, and we know from the Lemma that $m_{B i}^{\beta}=m_{A i}^{1}$.

Similarly,

$$
\frac{d m_{B i}^{\beta}}{d \delta_{i}}=-\frac{\frac{\partial \psi}{\partial m_{B i}}\left(\ln \left(\frac{\Psi_{i} \frac{\delta_{i}}{\delta} \theta R+\beta_{i}}{\Psi_{i} \frac{\delta_{i}}{\delta} \theta R+1}\right)+\frac{\Psi_{i} \frac{\delta_{i}}{\delta} \theta R}{\Psi_{i} \frac{\delta_{i}}{\delta} \theta R+\beta_{i}}-\frac{\Psi_{i} \frac{\delta_{i}}{\delta} \theta R}{\Psi_{i} \frac{\delta_{i}}{\delta} \theta R+1}\right)}{X_{B i}}
$$

The sign of this expression equals the sign of the numerator. For $\beta_{i}$ close to one, the numerator approximately equals ${ }^{7}$

$$
\frac{\partial \psi}{\partial m_{B i}}\left(\left(\frac{\Psi_{i} \frac{\delta_{i}}{\delta} \theta R+\beta_{i}}{\Psi_{i} \frac{\delta_{i}}{\delta} \theta R+1}-1\right)+\frac{\Psi_{i} \frac{\delta_{i}}{\delta} \theta R}{\Psi_{i} \frac{\delta_{i}}{\delta} \theta R+\beta_{i}}-\frac{\Psi_{i} \frac{\delta_{i}}{\delta} \theta R}{\Psi_{i} \frac{\delta_{i}}{\delta} \theta R+1}\right)
$$

\footnotetext{
${ }^{7}$ We use the approximation $\ln x \approx x-1$ for $x$ close to one.
} 
which equals

$$
\frac{\partial \psi}{\partial m_{B i}}\left(\left(\frac{\Psi_{i} \frac{\delta_{i}}{\delta} \theta R+\beta_{i}}{\Psi_{i} \frac{\delta_{i}}{\delta} \theta R+1}-1\right)\left(1-\frac{\Psi_{i} \frac{\delta_{i}}{\delta} \theta R}{\Psi_{i} \frac{\delta_{i}}{\delta} \theta R+\beta_{i}}\right)\right),
$$

which is positive for $\beta_{i}>1$. Furthermore it is straightforward to check that the numerator of (31) is increasing in $\beta_{i}$. We conclude that for $\beta_{i}>1$,

$$
\frac{d m_{B i}^{\beta}}{d \delta_{i}}>0
$$

Consider then a group where $\beta_{i}<1$. When party $B$ is of type $\beta$, party $A$ campaigns in this group. Party $A^{\prime} s$ first order condition for choice of campaign expenditure in such groups (26) becomes

$$
-\frac{\partial \psi}{\partial m_{A i}} \delta_{i}(1-\pi) \ln \left(\frac{\Psi_{i} \frac{\delta_{i}}{\delta} \theta R+\beta_{i}}{\Psi_{i} \frac{\delta_{i}}{\delta} \theta R+1}\right)=\mu
$$

Implicit differentiation gives

$$
\frac{d m_{A i}^{1}}{d \beta_{i}}=\frac{-\frac{\partial \psi}{\partial m_{A i}} \frac{1}{\Psi_{i} \frac{\delta_{i}}{\delta} \theta R+\beta_{i}}}{X_{A i}}<0
$$

where

$$
\begin{aligned}
X_{A i} \equiv & \frac{\partial^{2} \psi}{\partial\left(m_{A i}\right)^{2}} \ln \left(\frac{\Psi_{i} \frac{\delta_{i}}{\delta} \theta R+\beta_{i}}{\Psi_{i} \frac{\delta_{i}}{\delta} \theta R+1}\right) \\
& +\left(\frac{\partial \psi}{\partial m_{A i}}\right)^{2}\left(\frac{\frac{\delta_{i}}{\delta} \theta R}{\Psi_{i} \frac{\delta_{i}}{\delta} \theta R+\beta_{i}}-\frac{\frac{\delta_{i}}{\delta} \theta R}{\Psi_{i} \frac{\delta_{i}}{\delta} \theta R+1}\right)
\end{aligned}
$$

Hence, comparing two groups $i$ and $j$ where $\beta_{i}<\beta_{j}<1$, party $A$ will campaign more in group $i$ than group $j$. The reason is that the surprise is larger in group $i$. The attached party $B$ treats group $i$ badly and $A$ has a strong interest in revealing that. Similarly, when $B$ is neutral, it has a strong interest in revealing that to group $i: B$ of type $\beta$ campaigns as much as $A$ does when $B$ is of type 1 in group $i$, cf. the Lemma. Again it is also true that

$$
\frac{d m_{A i}^{1}}{d \delta_{i}}>0
$$


Party $A$ also addresses mobile groups.

Lemma 4 follows directly from the above total derivatives.

\section{References}

[1] Alvarez, R.M. (1998), Information and Elections. Ann Arbor: The University of Michigan Press.

[2] Baron, D. P. (1994), "Electoral Competition with Informed and Uninformed Voters." American Political Science Review, 88, 33-47

[3] Besley, T. and R. Burgess (2000): "The Political Economy of Government Responses: Theory and Evidence from India", mimeo, London School of Economics.

[4] Butters, G. (1977), "Equilibrium Distribution of Sales and Advertising Prices", Review of Economic Studies, 44(3), 465-491

[5] Coate, S. (2001), "Political Competition with Campaign Contributions and Informative Advertising", mimeo, Cornell University

[6] Coate, S. (2002), "Power-Hungry Candidates, Policy Favors and Pareto Improving Campaign Contribution Limits", mimeo Cornell University

[7] Dahlberg, M. and E. Johansson (2002), "On the Vote-Purchasing Behavior of Incumbent Governments", American Political Science Review, $96(1), 27-40$

[8] Dixit, A. and J. Londregan (1998), "The Determinants of Success of Special Interestes in Redistributive Politics", The Journal of Politics, $58,1132-1155$

[9] Friedman, J.W. (1983), "Advertising and Oligopolistic Equilibrium." The Bell Journal of Economics 14: 464-473. 
[10] Gerber, A. (1998), "Estimating the Effect of Campaign Spending on Senate Election Outcomes using Instrumental Variables", American Political Science Review, 92, 401-411

[11] Green, D.P., and J.S. Krasno (1988), "Salvation for the Spendthrift Incumbent: Reestimating the Effects of Campaign Spending in House Elections", American Journal of Political Science, 32, 884-907

[12] Grossmann, G.M and C. Shapiro (1984), "Informative Advertising with Differentiated Products", Review of Economic Studies, 51, 63-81.

[13] Holbrook, T.M.(1996). Do Campaigns matter?. Thousand Oaks: Sage Publications.

[14] Just, M., A. Crigler and L. Wallach (1990). "Thirty Seconds or Thirty Minutes: What Viewers Learn from Spot Advertisements and Candidate Debates." Journal of Communication 40: 120-133.

[15] Lindbeck, A. and J. Weibull (1987), "Balanced Budget Redistribution as the Outcome of Political Competition", Public Choice, 52, 273-297

[16] McKelvey, R. and P. Ordeshook (1987), "Elections with Limited Information: A Multidimensional Model." Mathematical Social Science 14:77-99.

[17] Ortuno-Ortin I. and C. Schultz, (2000) "Public Funding of Political Parties", CES-ifo Working Paper No. 368

[18] Persson, T. and G. Tabellini (2000), "Political Economics." MIT Press, Cambridge.

[19] Potters, J, R. Sloof and F. van Winden (1997), "Campaign Expenditures, Contributions, and Direct Endorsements: The Strategic Use of 
Information and Money to Influence Voter Behavior", European Journal of Political Economy, 13, 1-31

[20] Pratt, A. (1999), "Campaing Advertising and Voter Welfare", mimeo, London School of Economics

[21] Pratt, A. (2000), "Campaign Spending with Officie-Seeking Politicians, Rational Voters, and Multiple Lobbies", mimeo, London School of Economics, forthcoming Journal of Economic Theory

[22] Schultz, C. (2002), "Policy Biases with Voters' Uncertainty about the Economy and the Government", European Economic Review; 46(3), 487-506.

[23] Strömberg, D. (1999): "Mass Media Competition, Political Competition and Public Policy", forthcoming Review of Economic Studies

[24] Strömberg, D. (2000): "Radio's Impact on Public Spending", mimeo, University of Stockholm

[25] Wittman, D. (1990). "Spatial Strategies when Candidates Have Policy Preferences," in J. Enelow and M. Hinich (Ed.), Advances in the Spatial Theory of Voting: Cambridge: CUP. 
EPRU - a Presentation

EPRU Staff

EPRU Research Plan

EPRU Annual Reports

EPRU News

Seminars

Visitors

Publications

Conferences and Workshops

Useful Links

Back to Main Page

EPRU Netværket

The EPRU Home Page is maintained by

Mirtha C. Saavedra

Updated 25-04-2003

\section{Welcome to}

\section{Economic Policy Research Unit (EPRU)}

A centre established in cooperation with the Danish National Research Foundation and the Institute of Economics, University of Copenhagen.

\section{NEW REPORT 1993-2002}

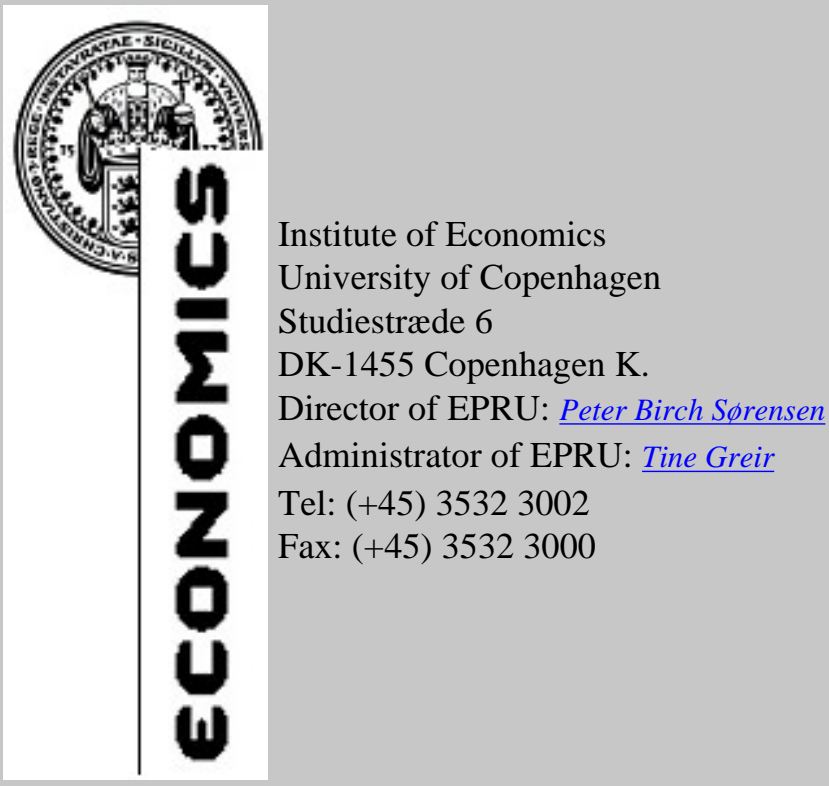

Next EPRU Seminar 